\title{
A Measure of Perceived Severity in Organizational Crises: A Multidimensional Scale Development and Validation
}

\author{
Ziyuan Zhou (D, Eyun-Jung Ki, and Kenon A. Brown \\ Department of Advertising and Public Relations, University of Alabama, \\ Tuscaloosa, Alabama, USA
}

\begin{abstract}
This study proposed a definition of perceived crisis severity and created a valid and reliable scale to measure the construct following Churchill's scale development procedure. The proposed scale, after rigorous pilot testing and exploratory and confirmatory factor analysis, contains 3 factors with 12 items. This study discusses potential applications of the developed measures and provides future research directions.
\end{abstract}

KEYWORDS: Perceived crisis severity; scale development; SCCT

Situational crisis communication theory (SCCT) is the most frequently tested theory in crisis communication research along with image repair theory (Avery, Lariscy, Kim, \& Hocke, 2010). SCCT is the first theory to integrate crisis situations with response strategies, arguing that the selection of a crisis response strategy is contingent on different factors. It helps practitioners form a complete picture of a crisis dynamic rather than only thinking about what to say. Since its introduction, scholars have tested intensifiers proposed by the theory, like prior reputation and crisis history (e.g., Coombs, 2004; Kiambi \& Shafer, 2016). As more evidence is gained through empirical research, one variable initially proposed by SCCT draws the least attention and only reaches inconsistent findings: crisis severity.

In the seminal empirical study, Coombs (1998) identified two intensifiers that strengthen stakeholders' responsibility attribution: crisis

CONTACT Ziyuan Zhou •E-mail: zzhou36@crimson.ua.edu • Department of Advertising and Public Relations, University of Alabama, Tuscaloosa, AL 35487, USA

๑ 2019 by Journal of International Crisis and Risk Communication Research. All rights reserved. 
history and the severity of damage. Severity of damage was negatively correlated with crisis responsibility in the original experiment (Coombs, 1998) and so was excluded in later SCCT studies (Coombs, 2007, 2010). Nonetheless, the concept of crisis severity continuously appears in crisis communication and management literature (Arpan \& Pompper, 2003; Arpan \& Roskos-Ewoldsen, 2005; Claeys, Cauberghe, \& Vyncke, 2010; Hong \& Len-Riós, 2015; Isaacson, 2012; Laufer, Gillespie, McBride, \& Gonzalez, 2005; Lee, 2004; Vassilikopoulou, Siomkos, Chatzipanagiotou, \& Pantouvakis, 2009). Scholars believe the intensity that stakeholders feel varies as the perceptions of crisis severity change. The negative outcomes of a crisis are influenced by the crisis severity, especially organizational reputation, such that as a crisis becomes more severe, organizational reputation suffers more (Claeys et al., 2010; Isaacson, 2012).

In addition to the theoretical implications for understanding crisis dynamics, crisis severity can also influence crisis managers' decisions. Stephens, Malone, and Bailey (2005) recommended considering the severity of a crisis when selecting one's response strategy. Crisis managers need to evaluate a crisis situation, especially its severity and scope, before developing appropriate response strategies. Crisis response strategies cannot be maximally effective if crisis managers underestimate or overestimate the magnitude of a crisis.

Despite the importance of crisis severity, there is no widely accepted definition. Studies that use the term crisis severity often refer to different meanings. This discrepancy limits researchers' understanding and analysis of this essential construct. More importantly, a lack of definition hinders the creation of a reliable and valid measurement. Current scales generally treat severity as a one-dimensional variable and ask only one question (Claeys et al., 2010; Laufer et al., 2005; Vassilikopoulou et al., 2009) or three similar questions (Arpan \& Pompper, 2003; Arpan \& Roskos-Ewoldsen, 2005; Hong \& Len-Riós, 2015). This oversimplifies the complexity of the construct. Without a valid measurement, findings from any research are questionable. Hence this study intends to develop a valid and reliable measurement of crisis severity to advance the field of crisis communication.

The purpose of this study is twofold. First, we propose a definition 
of perceived crisis severity by stakeholders and its dimensions using a comprehensive literature review. Second, based on the constructed definition, we develop a measure of perceived crisis severity and validate the scale by following Churchill's (1979) guidelines. Churchill proposed an eight-step scale validation process: specify the domain of construct, generate a sample of items, collect data, purify the measure, collect data, assess reliability, assess validity, and develop norms.

\section{Defining the Construct and Searching for Measurements}

\section{Perceived Crisis Severity Defined}

SCCT assumes that an organization's reputation is a valued resource that can be threatened by crises. During a crisis, an organization's goal is to evaluate the situation and select appropriate response strategies to protect its reputation (Coombs \& Holladay, 2002). Early SCCT studies discussed severity of damage (crisis severity) along with crisis responsibility and crisis history (Coombs, 1995, 1998; Coombs \& Holladay, 1996, 2002). Coombs (1995) argued that damage could be any form of death, injury, property destruction, or environmental harm (Coombs, 1995). Crisis severity was operationalized as "the amount of damage generated by a crisis including financial, human, and environmental damage" (Coombs \& Holladay, 2002, p. 169).

At the first empirical attempt, Coombs (1998) predicted that as the severity of crisis damage increases, an organization's image becomes more negative, and the organization's perceived crisis responsibility is strengthened. However, Coombs found the reverse of this hypothesis-minor degrees of severity incurred greater crisis responsibility attribution and more negative image evaluation. Coombs claimed that stakeholders' sympathy toward the organization caused the reverse finding. Lee (2004) similarly proposed that higher crisis severity leads to more crisis responsibility, more negative impressions, less sympathy, and less trust. Likewise, none of these hypotheses were significant. Park and Len-Riós (2010) followed this line of research and added some explanations. They hypothesized that people attribute more crisis responsibility to an organization when a consumer is the injured party. In contrast, if the injured party is the organization, people attribute 
less crisis responsibility. However, empirical evidence did not support their prediction. No interaction was found between crisis severity and injured party (Park \& Len-Riós, 2010).

While the aforementioned studies failed to find the hypothesized effects of crisis severity, other studies revealed that crisis severity is positively associated with stakeholders' blame and negatively associated with reputation and purchase intent (Arpan \& Roskos-Ewoldsen, 2005; Claeys et al., 2010; Isaacson, 2012; Laufer et al., 2005). Some researchers investigated crisis severity from a different angle, assuming it is important to minimize people's perceptions of crisis severity. These studies treated crisis severity as a dependent variable. Arpan and Pompper (2003) indicated that the "stealing thunder" strategy, which refers to "an admission of a weakness before that weakness is announced by another party" (p. 294), could effectively reduce crisis severity levels. Hong and Len-Riós (2015) also demonstrated that university sports crises cause higher perceptions of crisis severity than product-recall crises.

Although scholars extensively use the term crisis severity, definitions vary. As discussed previously, Coombs and Holladay (2002) defined crisis severity as "the amount of damage generated by a crisis including financial, human, and environmental damage" (p. 169). This definition indicates that crisis severity refers to the actual damage a crisis incurs. However, other scholars have examined crisis severity from stakeholders' points of view. Park and Len-Riós (2010) argued that "the severity of damage is not necessarily a function of actual damage, but of perceptions" (p. 595). They claimed that the perception of crisis severity can vary according to media portrayals and definitions. Claeys et al. (2010) also suggested that researchers use perceived crisis severity instead of the actual damage. The definition of a crisis as "the perception of an unpredictable event that threatens important expectancies of stakeholders and can seriously impact an organization's performance and generate negative outcomes" (Coombs, 2007, pp. 2-3) implies that the existence of a crisis is determined by stakeholders' perceptions. Even if an organization does not believe there is a crisis, the crisis exists as long as stakeholders believe it exists. The same logic should apply to the definition of crisis severity. Even if an organization does not believe a crisis is severe, the crisis is severe as long as stakeholders believe it is. 
As such, it is more significant to investigate perceived crisis severity rather than actual severity.

Although crisis severity is frequently discussed, no unified definition of the concept exists. This study defines perceived crisis severity as "stakeholders' objective and emotional assessment of the intensity of a crisis." This definition contains three key elements. First, this study considers crisis severity from stakeholders' perspectives. A crisis is severe as long as stakeholders perceive it to be severe. Second, the perceived severity of a crisis can vary among different stakeholder groups. For example, a crisis situation might be severe to a community but not to investors. Third, the assessment of severity is based on both cold and hot judgments. Cold judgment refers to objective assessments, such as who is affected by the crisis or, whether the crisis impacts my own life. Stakeholders use logic and knowledge to infer the severity of a crisis. Hot judgment refers to the uneasiness a crisis brings people. People are emotional, and so the initial psychological impact of a crisis on people largely influences people's judgments. As Coombs and Holladay (2005) have discussed, a crisis usually generates negative emotions among stakeholders. Evaluations of crisis severity are less likely to be based solely on critical thinking; instead, cognition and emotion together influence stakeholders' judgments.

\section{Current Measures of Crisis Severity}

Scholars in crisis communication commonly use survey and experimental methods to examine perceived crisis severity. Experimental studies manipulate crisis situations to control severity. Coombs's (1998) seminal work labeled little property damage and nonserious injuries as minor damage and huge property damage and serious injuries as major damage. Lee (2004) regarded 200 injuries as a severe crisis and 300 deaths as an extremely severe crisis resulting from a plane crash. Isaacson (2012) regarded the theft of $\$ 15,000$ a high-severity crisis and the theft of a small amount of money a low-severity crisis. Although these experimental studies explained the effect of perceived crisis severity, their contribution to crisis severity measurement is limited. As crisis types diversify, some crises do not cause death, injury, or property damage but could still be categorized as mild or severe in terms of crisis 
severity. For example, data breach crises almost always influence large numbers of people and cause concerns about the security of their identities and financial information, though no death or injury is involved.

In survey research, scholars have used single-item scales to measure crisis severity, for example, asking how severe respondents consider the crisis situation to be based on either a 10-point scale or an 11-point scale (Claeys et al., 2010; Laufer et al., 2005; Vassilikopoulou et al., 2009). Other scholars have used multiple-item scales, for example, asking about participants' feelings of seriousness, badness, and extremeness regarding a crisis (Arpan \& Pompper, 2003; Arpan \& Roskos-Ewoldsen, 2005; Hong \& Len-Riós, 2015).

These crisis severity scales have two major drawbacks. First, nearly all studies treat crisis severity as a one-dimensional construct. Some ask only one question (Claeys et al., 2010; Laufer et al., 2005; Vassilikopoulou et al., 2009). Even scales with multiple items do not demonstrate different dimensions in crisis severity (Arpan \& Pompper, 2003; Arpan \& Roskos-Ewoldsen, 2005; Hong \& Len-Riós, 2015). Second, none of the studies have considered the perspectives of publics. The scales do not answer to whom a crisis is severe. Stakeholders who are more affected by the crisis are likely to have different crisis severity perceptions than those who are less affected by the crisis. In short, perceived crisis severity differs among stakeholders.

\section{Proposed Dimensions and Items}

Perceived crisis severity is not regarded as a multidimensional construct and does not have a widely accepted measurement. To develop a multidimensional measure of perceived crisis severity, the researchers consulted with literature from related disciplines, including psychology and marketing.

\section{Psychological Origin: Defensive Attribution}

The concept of defensive attribution initially appeared in psychology literature as early as the 1960s. Walster (1966) argued that the worse the consequences of an accident, the greater responsibility people would attribute to the wrongdoer. She explained that if a person only suffers 
small losses, people commonly believe the unpleasant thing could happen to anyone even if he or she did nothing wrong. On the other hand, if an accident becomes more severe and unpleasant, people feel the unpleasant thing could happen not only to "anybody" but to "you." In this situation, people seek someone who is responsible for the accident to assure themselves. Fiske and Taylor (1991) elaborated on the defensive attribution hypothesis in a similar fashion. An accident becomes less tolerable as its consequences become more severe. People are afraid similar things will happen to them; blaming the person who causes the accident makes it predictable and avoidable (Fiske \& Taylor, 1991).

Since the introduction of defensive attribution, various studies have been conducted to test its hypotheses. Most studies have confirmed the positive relationship between outcome severity and responsibility attribution, though some research has found the relationship to be insignificant or even negative (Shaver, 1970; Thomas \& Parpal, 1987; Walster, 1966). The results of two meta-analyses, however, generally confirm the defensive attribution hypothesis (Burger, 1981; Robbennolt, 2000).

As studies on defensive attribution accumulated, the concept was introduced to marketing communication. Laufer et al. (2005) claimed that findings of defensive attribution in psychology could also shed light on marketing communication research. The authors argued that the severity of product failure and product-harm crises vary. Minor problems and severe problems will create different blame attribution. However, blame attribution may also influence how people perceive the severity of a crisis. In other words, blame attribution could be both an antecedent and outcome of severity. The two concepts are intertwined and influence each other. Therefore this study regards stakeholders' blame as a tentative dimension of perceived crisis severity. Although blame cannot determine severity, the magnitude of stakeholders' blame attribution reflects their perceived crisis severity.

\section{Service Failure Severity: A Service Marketing Perspective}

Service failure severity (also known as the magnitude of service failure) is a service marketing concept comparable to crisis severity. Service failure severity is defined as "a customer's perceived intensity of a service problem” (Weun, Beatty, \& Jones, 2004, p. 135). Perceived loss 
is closely interwoven with service failure severity. The more intense or severe a service problem, the greater the customer's perceived loss (Chuang, Cheng, Chang, \& Yang, 2012; Weun et al., 2004). Riaz and Khan (2016) even defined service failure severity as "the measure of the enormity of the loss that a consumer faces as an outcome of service failure" (p. 426). In a similar vein, empirical studies confirmed that as service failure severity increases, customers' dissatisfaction (McCollough, 2009), disloyalty (Wang, Wu, Lin, \& Wang, 2011), and negative word of mouth (Weun et al., 2004) increase correspondingly.

Service failure severity and crisis severity bear two similarities. First, service failure and crises are negative and unexpected events that occur to a person or an organization. They both bring financial and reputational losses. Second, the magnitude of both service failure severity and crisis severity is determined by people's perceptions. The difference between the two concepts lies in audiences. For a service failure, the audience is primarily customers. For a crisis, an organization should communicate with several stakeholder groups in addition to customers (e.g., shareholders, employees).

Regardless of differences between the two concepts, one could adopt ideas and dimensions from service failure severity measurement when developing a crisis severity scale. Two measurement scales are widely applied in service marketing. One scale contains three items (Inyang, 2015; Wang et al., 2011; Weun et al., 2004), and the other one includes four items (Riaz \& Khan, 2016; Tsarenko \& Tojib, 2012). These items measure two concepts: emotion and relevance. Items measuring "angry," "unpleasant," and "stress" represent human emotions. These items correspond to Lee's (2004) argument that high crisis severity may incur negative emotional reactions. Therefore, this study deems emotion an important dimension of crisis severity. Other items measure the level of inconvenience a service failure brings to participants, which is conceptually similar to relevance in crisis communication. Lee contended that the more severe the crisis, the more personal involvement/relevance it has. Laufer and colleagues (2005) argued that relatively minor problems involve mild inconvenience to stakeholders. Thus relevance is another important dimension of severity. These two dimensions from service failure severity scales will be referenced as relevance-induced severity and 
emotion-induced severity. Finally, this study regards blame attribution from defensive attribution literature as a third dimension of perceived crisis severity that will be referenced as blame-induced severity.

Thus the initial construct contains three dimensions: blame-induced, relevance-induced, and emotion-induced severity. Since the three dimensions are similar to existing concepts in crisis communication, we consulted existing measures of these variables. Blame-induced severity items were adopted from the items of an organizational crisis responsibility scale (Brown \& Ki, 2013). Emotion-induced severity items were drawn from service failure severity scales (Tsarenko \& Tojib, 2012; Weun et al., 2004). Relevance-induced severity items were drawn from the personal involvement inventory (Zaichkowsky, 1994) and service failure severity scales (Tsarenko \& Tojib, 2012; Weun et al., 2004). To enlarge the initial item pool, researchers referred to dictionary definitions of blame, emotion, and relevance and created several new items. Accordingly, the following research question is proposed:

RQ1: What is a reliable and valid measure of perceived crisis severity?

\section{Pilot Testing}

Pilot tests were conducted prior to the main data collection. First, a group of doctoral students specializing in the communication discipline were asked to read five crisis scenarios designed to stimulate research subjects and evaluate initial scale items. This procedure improved the logic and readability of the crisis scenarios.

After the first pilot test, the researchers invited nine experts in crisis communication to evaluate the quality of the scale. The study employed Lawshe's (1975) quantitative approach, the content validity ratio (CVR), to determine the agreement among experts. The scholars read the definitions of the target construct and its three dimensions and then were asked to evaluate the proposed dimensions and items based on three categories: essential, useful but not essential, and not necessary. Based on these experts' evaluations, CVRs were computed, and only two items passed the recommended cutoff of .78 (Lawshe, 1975), while the other items were challenged by the scholars. In addition 
to completing the CVR form, scholars were asked to comment on the adequacy of the three dimensions to measure the perceived crisis severity construct and the accuracy of the definitions. The blame-induced dimension reached the least agreement of the three dimensions. The expert scholars questioned the discriminant validity of this dimension, arguing that some crises are inherently severe but unnecessarily cause strong blame, such as natural disasters. These comments were applied to revise the items. After the two rounds of reviews by students and scholars separately, initial content validity was achieved.

\section{Crisis Situation Manipulations}

All crises used in this study happened between 2014 and 2016 and are well known by publics in the United States. The five crisis situations included the Ashley Madison data breach, the University of Missouri racism protests, the Wells Fargo fraudulent account scandal, the Volkswagen emission scandal, and Malaysia Airlines Flight 370. Each crisis scenario was presented in a short paragraph ranging from 96 to 123 words. Only basic information was given, such as time, organization name, the cause of the crisis, and victims involved.

\section{Full Administration}

\section{Sample}

The study recruited 300 participants from Amazon Mechanical Turk, but after a comprehension check, only data from 290 participants were kept for further analysis. The sample primarily consisted of males (61\%; $n=177)$, while females made up $38.6 \%(n=112)$. The racial makeup of the sample was as follows: $76.6 \%$ Caucasian $(n=222), 10.7 \%$ Asian and Pacific Islander $(n=31), 6.9 \%$ African American $(n=20)$, and $6.6 \%$ Latinx or Hispanic $(n=19)$. Some subjects identified themselves as multiracial. The average age of the participants was 34.79 years, with a range between 20 and 70 years. This data set was used to conduct all statistical analyses, except confirmatory factor analysis. For confirmatory factor analysis, data were collected from 182 participants on Amazon Mechanical Turk. About half of the sample were male $(n=90)$ and half were female $(n=92)$. The racial makeup of the sample was as follows: $40.7 \%$ Asian $(n=74), 38.5 \%$ Caucasian $(n=70), 7.1 \%$ 
Native American $(n=13), 6 \%$ African American $(n=11)$, and 5.5\% Latinx or Hispanic $(n=10)$. The average age of the participants was 29.18 years, with a range between 18 and 67 years. ${ }^{1}$

\section{Procedures}

The study created five crisis scenarios, which covered different types of organizations and crises. Participants were randomly assigned to one of the five scenarios. After reading a crisis, participants were required to answer two comprehension check questions. One asked them to identify the type of the crisis, and the other was to identify the name of the organization. Participants who failed to give correct answers were excluded from further analysis to ensure data quality. Participants were then asked to rate their agreement on measurement items based on a 7-point Likert scale ranging from 1 (strongly disagree) to 7 (strongly agree).

\section{Measure Purification}

A correlation matrix was generated among all 24 items. The initial check indicated that all items in the blame-induced dimension were not correlated with other items, $p>.05$. This result raises convergent validity issues. Exploratory factor analysis (EFA) was implemented, and the result demonstrated that the factor containing all blame-induced severity items had low correlation with other factors (with relevance, $r=.00$; with emotion, $r=.06$ ). The test further confirmed the convergent validity problem. Based on panel suggestions and the EFA result, the study theoretically and statistically rejected the feasibility of the blameinduced severity dimension and removed the seven items. Therefore the statistical examination started from two dimensions with 17 items to develop the scale for perceived crisis severity.

\section{Validity Assessment}

\section{Exploratory Factor Analysis}

Before conducting EFA, the correlation matrix was first assessed to determine factorability of the matrix. Three examinations were applied: (a) Bartlett's test of sphericity, (b) the Kaiser-Meyer-Olkin (KMO) 
test, and (c) individual measures of sampling adequacy (MSA). Pett, Lackey, and Sullivan (2003) recommended that the test of sphericity should be significant, KMO should be higher than .7, and MSA should be higher than .7. In the analysis, KMO equaled .933, and Bartlett's test of sphericity was .oo. The values of 24 MSAs ranged from .888 to .975 . All indicators showed the data set is factorable.

The determination of the number of factors was based on multiple standards: (a) eigenvalue greater than 1, (b) scree plot, (c) percentage of variance extracted, (d) Velicer's minimum average partial (MAP) test, and (e) parallel analysis. First, according to the Kaiser-Guttman rule of eigenvalues greater than 1 , three factors were extracted. An examination of the scree plot also confirmed a three-factor solution. The EFA with principal component analysis (PCA) method indicated that the three factors explained $72.13 \%$ of the total variance, while EFA with principal axis factoring (PAF) showed that the three factors explained $66.25 \%$ of the total variance. However, the standard of eigenvalue greater than 1 is widely criticized by scholars. Gorsuch (1983) claimed that this method is only accurate when the number of variables is smaller than 40 and the sample size is large. Zwick and Velicer (1986) were also strongly against using this rule. Therefore, a MAP test was implemented, and the result confirmed the three-factor conclusion. Fifth, the study executed parallel analysis with both PCA and PAF methods. The PCA method indicated that two factors should be extracted, while the PAF method recommended four factors. Based on these five test results, we selected the three-factor model supported by four of the five tests.

The EFA using PAF method based on three factors was executed. The study first employed two types of oblique rotations (direct oblimin and promax), since they assume correlation among factors. Nevertheless, both rotations generated complex structure matrices that contained serious cross-loading issues. Thus the researchers decided to use orthogonal rotation (varimax) to increase interpretability. The rotated factor matrix created by orthogonal rotation was more interpretable than the structure matrix generated by oblique rotation. Then, five items with weak loading and cross-loading problems were removed based on three standards: (a) item loadings on the primary factor must be above .6, (b) the difference between the highest loading and the second 
highest loading must be at least .3 , and (c) the commonalities must be higher than .5. After removing the problematic items, the study ran the EFA using PAF method with varimax rotation the second time and generated ideal factor loadings for the scale.

Based on the EFA report, the relevance-induced dimension split into two factors. One factor was defined as relevance. The other factor was defined as interest-induced severity, since the four items concerned stakeholders' interests about a crisis. A detailed conceptualization is discussed in a later section. The three-factor model (emotion, relevance, and interest) with 12 items was retained for further analysis (interest, $\alpha=.91, M=4.84, S D=.22$; emotion, $\alpha=.94, M=3.68, S D=.14$; relevance, $\alpha=.88, M=3.41, S D=.51)$.

\section{Confirmatory Factor Analysis (CFA)}

CFA was used to further test construct validity and the relationships among the three dimensions. According to $\mathrm{Hu}$ and Bentler (1999), a good model should pass the following cutoffs: .06 or smaller for root mean square error of approximation (RMSEA); .95 or greater for comparative fit index (CFI), normed-fit index (NFI), and incremental fit index (IFI); and normed chi-square smaller than 5. The initial model fit indicators did not meet these standards. RMSEA was larger than 1, and other model fit indices were smaller than .95. Covariances among error terms were added according to modification indices, and the CFA was rerun. The second CFA demonstrated that the model ideally fit the data. All modification indices were acceptable, ranging from 4.06 to 4.83. Other indicators also showed favorable results, $\chi^{2}=66.331$, $d f=38, \chi^{2} / d f=1.411($ RMSEA $=.048, \mathrm{CFI}=.990, \mathrm{NFI}=.966, \mathrm{IFI}=.990)$.

\section{Reliability Assessment}

The reliability of the overall scale was $.95(M=4.87, S D=.29)$. The reliabilities of the three dimensions were also acceptable: interest-induced $(\alpha=.92, M=5.24, S D=.07)$, emotion-induced $(\alpha=.91, M=4.69$, $S D=.14)$, and relevance-induced $(\alpha=.91, M=4.70, S D=.16)$. The appendix provides the final scale. 


\section{Discussion}

Two purposes of this study are (a) to offer a definition of perceived crisis severity and (b) to develop a valid and reliable scale to measure the construct. Following Churchill's (1979) scale development guidelines, a three-dimensional scale with 12 items was found to be reliable and valid.

Through theoretical and statistical investigation, the study proposed a three-dimensional scale with 12 items to measure perceived crisis severity. Blame-induced severity, an initially proposed dimension, was excluded from the study based on theoretical and statistical examination. The remaining two dimensions with 17 items generated three factors. After a preliminary EFA test and structure-based CFA test, the relevance-induced severity dimension from the initial scale was further divided into two factors, relevance-induced severity and interest-induced severity. The definitions of emotion-induced severity and relevance-induced severity were retained. Emotion-induced severity denotes a member of a public's affective response to a crisis. Relevance-induced severity is defined as the extent to which a member of a public feels involved in and affected by a crisis. Interest-induced severity was reconceptualized based on the theme of the measurement items. Interest-induced severity represents the extent to which a member of a public desires to know more about a crisis. The threedimensional scale contains four items for emotion-induced severity, three items for relevance-induced severity, and four items for interestinduced severity.

The three dimensions are strongly associated with perceived crisis severity. As a crisis becomes more severe, stakeholders may become more emotional because they are surprised or scared by the situation. A severe crisis may interest stakeholders because it might threaten their safety. Stakeholders are also willing to know more about the situation and how to protect themselves. Stakeholders might feel more personally involved, thus perceiving greater relevance as the situation becomes more severe, since they are potential victims of a similar crisis. The three dimensions are also associated with each other. Stakeholders may not be interested in the situation if the crisis is not relevant to them. If stakeholders do not feel involvement or relevance regard- 
ing the crisis, they are less likely to be emotional about the crisis.

This new crisis severity scale has a distinct advantage over other existing scales because it is the first scale to consider dimensionality issues. Scales with only one or three items lack accuracy because a respondent's reflection could be easily influenced by his or her instant thoughts. In addition, if a scale only contains one item, it cannot assess reliability or validity. With the creation of this multidimensional scale, researchers may check reliability and validity when they measure crisis severity.

To the best of the researchers' knowledge, this study is the first to operationalize the concept of perceived crisis severity and develop a multidimensional scale for the construct. Since the concept of perceived crisis severity has been discussed and examined in crisis literature over time, the operational definition and new scale could generate further discussion and facilitate this line of research. The inconsistent findings revealed in previous studies could potentially be resolved by the employment of this scale. In addition, since SCCT initially proposed this concept, the operationalization of perceived crisis severity could help other scholars reconsider the importance of the construct in the SCCT model. As crisis severity generates different public perceptions of an organization and a crisis situation, SCCT should consider if perceived crisis severity influences other variables in the model. Since SCCT aims to explain a crisis dynamic and guide the response strategy selection process, the addition of the crisis severity construct can increase the explanatory power of the model.

Practically, crisis managers could consider the dimensions included in the new scale when they want to assess whether the influence of a crisis is powerful. As Coombs (1995) stated, the severity of a crisis influences an organization's strategy selection. In a severe crisis, publics expect certain explanations about the situation, and an organization should seek strategies to soothe publics (Coombs, 1995). Therefore crisis managers could survey a small group of stakeholders about perceived crisis severity. If the result shows that the crisis is severe, crisis managers must pay more attention to the situation and design strategies that do not antagonize stakeholders.

The proposed dimensions could also guide an organization's crisis message selection process. In certain situations, an organization may 
hope to intentionally increase or decrease stakeholders' perceived crisis severity. For example, when Zika virus hits, people may not be fully aware of the potential harm it may bring. However, the government wants to increase people's awareness of the issue and intentionally increase people's perceived crisis severity. When drafting public messages, they should think about how to make Zika virus relevant to people. In addition, the message should also arouse people's emotions, such as fear and stress. The message should also arouse people's interest in keeping track of the development of the crisis.

\section{Limitations and Future Research}

The study bears three major limitations. The first limitation resides in crisis situations. Although the study included five crisis scenarios to cover multiple types of crises and organizations, it is still premature to assume that the scale applies to all types of crises. Second, since the study employed real crises and organizations, prior reputation might contaminate participants' perceptions of severity. Third, different types of validity such as discriminant validity, convergent validity, and predictive validity, were not discussed in this study.

Future research should apply the new scale to test the key relationships in the SCCT model, especially the relationship between severity and responsibility as well as the relationship between severity and reputation. Establishing and confirming these relationships would further explicate and improve SCCT.

Regardless of its limitations, this study provides a useful instrument to measure an important construct, perceived crisis severity in crisis communication, and the researchers believe that adding a perceived crisis severity variable can help form a holistic view of crisis situations and advance the understanding of crisis dynamics. 


\section{Appendix: The Final Perceived Crisis Severity Scale}

Interest-Induced Severity $(\alpha=.92, M=5.24, S D=.07)$

IIS 1: I care about the crisis.

IIS 2: Further news about the incident is of my interest.

IIS 3: I hope to know more about the incident.

IIS 4 : I think the crisis interests me.

Emotion-Induced Severity $(\alpha=.91, M=4.69, S D=.14)$

EIS 1: The crisis incurred my sense of stress.

EIS 2: I feel quite anxious about the crisis.

EIS 3: My apprehension grew as I knew more about the crisis.

EIS 4: I'm worried about the crisis situation.

Relevance-Induced Severity $(\alpha=.91, M=4.70, S D=.16)$

RIS 1: I feel influenced by this crisis.

RIS 2: I feel involved in the crisis.

RIS 3: I find this crisis relevant to me.

RIS 4: The crisis is meaningful to me. 
Ziyuan Zhou is a doctoral student at the University of Alabama. His research focuses on stakeholders' perceptions and behaviors during corporate crises as well as crisis communication strategies. He received his master's degree in public relations from Boston University.

Eyun-Jung Ki, $\mathrm{PhD}$, is a professor in the Department of Advertising and Public Relations at the University of Alabama. She has published more than 50 peer-reviewed articles and was the lead editor of Public Relations as Relationship Management: A Relational Approach to the Study and Practice of Public Relations (2nd ed.). Her primary research areas are organization-public relationships, emerging media, crisis communication, and global public relations.

Kenon A. Brown, PhD, is an associate professor and the graduate coordinator for the Department of Advertising and Public Relations at the University of Alabama, as well as the 2017 recipient of the Early Career Research Award from the International Communication Association's Sports Communication Interest Group. His research interests include image and reputation management, particularly in sports, and minority recruitment in mass communication. Kenon is also the programming director for the Alabama Program in Sports Communication and works closely in multiple capacities with several sport and entertainment organizations, including the International Olympic Committee, Twitch, FOX Sports, NASCAR, and the Country Music Association.

\section{ORCID}

Ziyuan Zhou (i) https://orcid.org/oooo-0oo2-2264-7281

\section{Note}

1. Both data sets include missing values in gender and race and people who identify themselves as multiracial. Therefore the gender and race breakdowns do not equal overall sample size. 


\section{References}

Arpan, L. M., \& Pompper, D. (2003). Stormy weather: Testing "stealing thunder" as a crisis communication strategy to improve communication flow between organizations and journalists. Public Relations Review, 29, 291-308. https://doi.org/10.1016/s0363-8111(03)ooo43-2.

Arpan, L. M., \& Roskos-Ewoldsen, D. R. (2005). Stealing thunder: Analysis of the effects of proactive disclosure of crisis information. Public Relations Review, 31, 425-433. https://doi.org/10.1016/j.pubrev.2005.05.003.

Avery, E. J., Lariscy, R. W., Kim, S., \& Hocke, T. (2010). A quantitative review of crisis communication research in public relations from 1991 to 2009. Public Relations Review, 36, 190-192. https://doi.org/10.1016/j.pubrev.2010.01.001.

Brown, K. A., \& Ki, E. J. (2013). Developing a valid and reliable measure of organizational crisis responsibility. Journalism \& Mass Communication Quarterly, 90, 363-384. https://doi.org/10.1177/1077699013482911.

Burger, J. M. (1981). Motivational biases in the attribution of responsibility for an accident: A meta-analysis of the defensive-attribution hypothesis. Psychological Bulletin, 90, 496-512. https://doi.org/10.1037/0033-2909.90.3 .496.

Chuang, S. C., Cheng, Y. H., Chang, C. J., \& Yang, S. W. (2012). The effect of service failure types and service recovery on customer satisfaction: A mental accounting perspective. Service Industries Journal, 32, 257-271. https://doi.org/10.2139/ssrn.1869434

Churchill, G. A. (1979). A paradigm for developing better measures of marketing constructs. Journal of Marketing Research, 16, 64-73. https://doi .org/10.2307/3150876

Claeys, A. S., Cauberghe, V., \& Vyncke, P. (2010). Restoring reputations in times of crisis: An experimental study of the situational crisis communication theory and the moderating effects of locus of control. Public Relations Review, 36, 256-262. https://doi.org/10.1016/j.pubrev.2010.05.004

Coombs, W. T. (1995). Choosing the right words: The development of guidelines for the selection of the "appropriate" crisis-response strategies. Management Communication Quarterly, 8, 447-476. https://doi.org/10.1177 /0893318995008004003

Coombs, W. T. (1998). An analytic framework for crisis situations: Better responses from a better understanding of the situation. Journal of Public 
Relations Research, 10, 177-191. https://doi.org/10.1207/s1532754xjprr1003 $-02$

Coombs, W. T. (2004). Impact of past crises on current crisis communication: Insights from situational crisis communication theory. Journal of Business Communication, 41, 265-289. https://doi.org/10.1177/o021943604265607

Coombs, W. T. (2007). Protecting organization reputations during a crisis: The development and application of situational crisis communication theory. Corporate Reputation Review, 10, 163-176. https://doi.org/10.1057 /palgrave.crr.1550049

Coombs, W. T. (2010). Parameters for crisis communication. In W. T. Coombs \& S. J. Holladay (Eds.), The handbook of crisis communication (pp. 17-53). Malden, MA: Blackwell. https://doi.org/10.1002/9781444314885.ch1

Coombs, W. T., \& Holladay, S. J. (1996). Communication and attributions in a crisis: An experimental study in crisis communication. Journal of Public Relations Research, 8, 279-295. https://doi.org/10.1207/s1532754xjprro804 -04

Coombs, W. T., \& Holladay, S. J. (2002). Helping crisis managers protect reputational assets: Initial tests of the situational crisis communication theory. Management Communication Quarterly, 16, 165-186. https://doi .org/10.1177/089331802237233

Coombs, W. T., \& Holladay, S. J. (2005). An exploratory study of stakeholder emotions: Affect and crises. In N. M. Ashkanasy, W. J. Zerbe, \& C. E. J. Hartel (Eds.), Research on emotion in organizations (pp. 263-280). Bingley, England: Emerald Group. https://doi.org/10.1016/s1746-9791(05)01111-9 Fiske, S. T., \& Taylor, S. E. (1991). Social cognition: From brains to culture (2nd ed.). New York, NY: McGraw-Hill.

Gorsuch, R. L. (1983). Factor analysis (2nd ed.). Mahwah, NJ: Erlbaum.

Hong, S., \& Len-Riós, M. E. (2015). Does race matter? Implicit and explicit measures of the effect of the PR spokesman's race on evaluations of spokesman source credibility and perceptions of a PR crisis' severity. Journal of Public Relations Research, 27, 63-80. https://doi.org/10.1080/1062726x.2014.929502 Hu, L. T., \& Bentler, P. M. (1999). Cutoff criteria for fit indexes in covariance structure analysis: Conventional criteria versus new alternatives. Structural Equation Modeling: A Multidisciplinary Journal, 6, 1-55. https://doi .org/10.1080/10705519909540118

Inyang, A. E. (2015). The buffering effects of salesperson service behaviors on 
customer loyalty after service failure and recovery. Journal of Managerial Issues, 27, 102-119. https://www.jstor.org/stable/44113686

Isaacson, T. E. (2012). Evaluating the crisis response strategies of a university basketball program: How do reactions differ based on apologies, crisis severity, and team identification? (Unpublished doctoral dissertation). Michigan State University, East Lansing.

Kiambi, D. M., \& Shafer, A. (2016). Corporate crisis communication: Examining the interplay of reputation and crisis response strategies. Mass Communication and Society, 19, 127-148. https://doi.org/10.1080/15205436.2015 .1066013

Laufer, D., Gillespie, K., McBride, B., \& Gonzalez, S. (2005). The role of severity in consumer attributions of blame: Defensive attributions in product-harm crises in Mexico. Journal of International Consumer Marketing, 17, 33-50. https://doi.org/10.1300/jo46v17no2_03

Lawshe, C. H. (1975). A quantitative approach to content validity. Personnel Psychology, 28, 563-575. https://doi.org/10.1111/j.1744-6570.1975.tbo13 93.X

Lee, B. K. (2004). Audience-oriented approach to crisis communication: A study of Hong Kong consumers' evaluation of an organizational crisis. Communication Research, 31, 600-618. https://doi.org/10.1177/009365020 4267936

McCollough, M. A. (2009). The recovery paradox: The effect of recovery performance and service failure severity on post-recovery customer satisfaction. Academy of Marketing Studies Journal, 13, 89-104.

Park, S. A., \& Len-Ríos, M. E. (2010). Who suffers? The effect of injured party on attributions of crisis responsibility. In T. W. Coombs \& S. J. Holladay (Eds.), The handbook of crisis communication (pp. 591-606). Malden, MA: Blackwell.

Pett, M. A., Lackey, N. R., \& Sullivan, J. J. (2003). Making sense of factor analysis: The use of factor analysis for instrument development in health care research. Thousand Oaks, CA: Sage.

Riaz, Z., \& Khan, M. I. (2016). Impact of service failure severity and agreeableness on consumer switchover intention: Mediating role of consumer forgiveness. Asia Pacific Journal of Marketing and Logistics, 28, 420-434. https://doi.org/10.1108/apjml-07-2015-0106

Robbennolt, J. K. (2000). Outcome severity and judgments of "responsibility": 
A meta-analytic review. Journal of Applied Social Psychology, 30, 2575-2609. https://doi.org/10.1111/j.1559-1816.200o.tbo2451.x

Shaver, K. G. (1970). Defensive attribution: Effects of severity and relevance on the responsibility assigned for an accident. Journal of Personality and Social Psychology, 14, 101-113.

Stephens, K. K., Malone, P. C., \& Bailey, C. M. (2005). Communicating with stakeholders during a crisis evaluating message strategies. Journal of Business Communication, 42, 390-419. https://doi.org/10.1177/0021943605 279057

Thomas, E. A. C., \& Parpal, M. (1987). Liability as a function of plaintiff and defendant fault. Journal of Personality and Social Psychology, 53, 843-857. https://doi.org/10.1037/0022-3514.53.5.843

Tsarenko, Y., \& Tojib, D. (2012). The role of personality characteristics and service failure severity in consumer forgiveness and service outcomes. Journal of Marketing Management, 28, 1217-1239. https://doi.org/10.1080/0267257X .2011 .619150

Vassilikopoulou, A., Siomkos, G., Chatzipanagiotou, K., \& Pantouvakis, A. (2009). Product-harm crisis management: Time heals all wounds? Journal of Retailing and Consumer Services, 16, 174-180. https://doi.org/10.1016/j .jretconser.2008.11.011

Walster, E. (1966). Assignment of responsibility for an accident. Journal of Personality and Social Psychology, 3, 73-79. https://doi.org/10.1037/hoo22733

Wang, Y. S., Wu, S. C., Lin, H. H., \& Wang, Y. Y. (2011). The relationship of service failure severity, service recovery justice and perceived switching costs with customer loyalty in the context of e-tailing. International Journal of Information Management, 31, 350-359. https://doi.org/10.1016/j .ijinfomgt.2010.09.001

Weun, S., Beatty, S. E., \& Jones, M. A. (2004). The impact of service failure severity on service recovery evaluations and post-recovery relationships. Journal of Services Marketing, 18, 133-146. https://doi.org/10.1108/o88760 40410528737

Zaichkowsky, J. L. (1994). The personal involvement inventory: Reduction, revision, and application to advertising. Journal of Advertising, 23, 59-70. https://doi.org/10.108o/oo913367.1943.10673459

Zwick, W. R., \& Velicer, W. F. (1986). Comparison of five rules for determining the number of components to retain. Psychological Bulletin, 99, 432-442. https://doi.org/10.1037/0033-2909.99.3.432 